OPEN ACCESS

Edited by:

Ülo Niinemets,

Estonian University of Life Sciences,

Estonia

Reviewed by:

Graciela Mónica Rusch,

Norwegian Institute for Nature

Research (NINA),

Norway

Miguel Portillo-Estrada

University of Antwerp,

Belgium

*Correspondence:

Aurora Gaxiola

Instituto de Ecología y Biodiversidad,

Alameda 340, Santiago, Chile agaxiola@uc.cl

Specialty section

This article was submitted to Functional Plant Ecology, a section of the journal Frontiers in Plant Science

Received: 10 November 2014 Accepted: 21 February 2015

Published: 17 March 2015

Citation

Gaxiola A and Armesto JJ (2015) Understanding litter decomposition in

semiarid ecosystems: linking leaf traits, UV exposure and rainfall

variability.

Front. Plant Sci. 6:140. doi: 10.3389/fp/s.2015.00140

\section{Understanding litter decomposition in semiarid ecosystems: linking leaf traits, UV exposure and rainfall variability}

\author{
Aurora Gaxiola ${ }^{1,2 *}$ and Juan J. Armesto ${ }^{1,2}$ \\ ${ }^{1}$ Instituto de Ecología y Biodiversidad, Santiago, Chile, ${ }^{2}$ Departamento de Ecología, Pontificia Universidad Católica de Chile, \\ Santiago, Chile
}

Differences in litter quality, microbial activity or abiotic conditions cannot fully account for the variability in decomposition rates observed in semiarid ecosystems. Here we tested the role of variation in litter quality, water supply, and UV radiation as drivers of litter decomposition in arid lands. And show that carry-over effects of litter photodegradation during dry periods can regulate decomposition during subsequent wet periods. We present data from a two-phase experiment, where we first exposed litter from a droughtdeciduous and an evergreen shrub to natural UV levels during five, rainless summer months and, subsequently, in the laboratory, we assessed the carry-over effects of photodegradation on biomass loss under different irrigation treatments representing the observed range of local rainfall variation among years (15-240 mm). Photodegradation of litter in the field produced average carbon losses of $12 \%$, but deciduous Proustia pungens lost $>25 \%$, while evergreen Porlieria chilensis less than $5 \%$. Natural exposure to UV significantly reduced carbon-to-nitrogen and lignin: $\mathrm{N}$ ratios in Proustia litter but not in Porlieria. During the subsequent wet phase, remaining litter biomass was lower in Proustia than in Porlieria. Indeed UV exposure increased litter decomposition of Proustia under low and medium rainfall treatments, whereas no carry-over effects were detected under high rainfall treatment. Consequently, for deciduous Proustia carry-over effects of UV exposure were negligible under high irrigation. Litter decomposition of the evergreen Porlieria depended solely on levels of rainfall that promote microbial decomposers. Our two-phase experiment revealed that both the carry-over effects of photodegradation and litter quality, modulated by inter-annual variability in rainfall, can explain the marked differences in decomposition rates and the frequent decoupling between rainfall and litter decomposition observed in semiarid ecosystems.

Keywords: C:N ratios, decomposition rates, ENSO, lignin, photodegradation, rainfall pulse, Chile

\section{Introduction}

Environmental controls on litter decomposition in terrestrial ecosystems are fundamentally related to differences in litter quality (e.g., element concentration in tissues) and local climate (temperature, precipitation). These two factors modulate microbial (and other decomposers) activity and thus mediate the processing of organic matter and the rates of internal ecosystem nutrient 
cycling (Meentemeyer, 1978; Aber et al., 1990; Couteaux et al., 1995; Aerts, 1997; Gholz et al., 2000; Hättenschwiler and Jørgensen, 2010). Nutrient concentrations (e.g., percent nitrogen), carbon-to-nitrogen (C:N) ratios, or lignin content of senescent foliage are all good indicators of litter quality for decomposers (Melillo et al., 1982; Parton et al., 2007). Local climatic variables such as temperature and moisture availability (Davidson and Janssens, 2006) regulate soil microbial activity through their effects on enzyme kinetics and nutrient diffusion. In semiarid ecosystems the interplay among all these and other variables affecting decomposition remains little understood. Understanding the drivers and mechanisms of nutrient cycling represents a conspicuous gap in our knowledge of the dynamics and functioning of semiarid ecosystems. Recent studies have suggested that factors, such as litter layer thickness (Henry et al., 2008), litter spatial distribution (Austin et al., 2009), soil microbial films (Barnes et al., 2012), and exposure to natural levels of UV radiation (Austin and Vivanco, 2006; Brandt et al., 2007, 2009) could also modulate litter decomposition rates and nutrient cycling in deserts.

Litter decomposition rates in semiarid ecosystems can be extremely variable (Zhang et al., 2008) and not directly dependent on precipitation, as for the same amount of rainfall (i.e., $250 \mathrm{~mm}$ ) litter decay rates (i.e., $k$ ) can vary from 0.1 to $1.2 \mathrm{y}^{-1}$ (Austin, 2011). Furthermore, decomposition studies have failed to document correlations between litter mass loss and differences in litter quality among species (Schaefer et al., 1985; Martínez-Yrízar et al., 2007; Austin, 2011). Considering that neither litter quality nor precipitation can fully account for the large differences in litter decay rates observed among semiarid ecosystems (Vossbrinck et al., 1979; Whitford et al., 1986; Austin and Vivanco, 2006; Gallo et al., 2006; Brandt et al., 2007; Zhang et al., 2008) other factors must be involved. This paper will explore how an additional factor, photodegradation, could play a role, in combination with litter quality and precipitation, to explain the observed variability in decay rates. Here we will focus primarily on the role of natural UV radiation during rainless periods, which is known to enhance the rates of biomass loss via photodecomposition or photodegradation, through the physicochemical breakdown of organic carbon compounds as a result of absorption of UV by litter (Vossbrinck et al., 1979).

High levels of solar radiation have for long been associated with carbon losses from organic matter especially in semiarid ecosystems (Pauli, 1964; Moorhead and Callaghan, 1994). However, until recently, studies have started to quantify the role of UV radiation on litter biomass losses. A field study in the Sonoran desert, estimated that $18-22 \%$ of litter mass loss of the evergreen shrub Larrea tridentata was attributable to nearambient solar UV radiation (Day et al., 2007). These authors identified lignin as the main organic compound lost from litter under natural UV action. Another study in California grasslands showed that grass and forb litter lost from 8 to $10 \%$ of their initial mass when exposed to natural solar radiation. Moreover, grass litter experienced $>50 \%$ reductions in lignin content (Henry et al., 2008). These studies indicate that natural UV exposure can modify litter quality by changing the concentration of aromatic and recalcitrant compounds, such as lignin, which are hard to decompose by soil microorganisms (Melillo et al., 1982; Gallo et al., 2009; Foereid et al., 2010). Recent studies have therefore started to suggest that the magnitude of UV-exposure effects on litter mass loss seems to be modulated by differences in leaf litter chemistry. For instance, a field experiment along an aridity gradient in North America (Gallo et al., 2009) showed greater mass loss due to UV exposure from high- than from low-quality litter (i.e., low lignin: $\mathrm{N}$ vs. high lignin: $\mathrm{N}$ ratios, respectively). These authors also found that mass loss from UV-exposed litter was more than twice as high as mass loss from UV-protected litter. However, the authors did not detect significant differences in decomposition rates between UV-exposed and UV-protected litter at sites receiving higher rainfall. Accordingly, exposure to UV radiation during dry periods can have significant positive effects on decomposition when microbial activity is limited by aridity (Henry et al., 2008). In a lab experiment, preexposure to artificial UV enhanced the digestibility of a C4 grass when subsequently decomposed under wetter conditions that favored microbial activity (Foereid et al., 2010). The authors suggested that exposure to UV radiation during dry periods was like a pre-treatment for decomposition during wetter conditions. Hence, carry-over effects of exposure to natural UV radiation could be more important in seasonally dry environments.

Enhanced decomposability after dry periods, however, can additionally depend on initial differences in leaf litter chemistry, which could interact with the subsequent microbial activity (Gallo et al., 2009; Foereid et al., 2010). We suggest therefore that carry-over effects of UV radiation on overall litter decomposition may depend not only on rainfall distribution and length of the dry period, but also on differences in leaf traits among coexisting species. This paper presents an experiment aimed at disentangling the relative contributions of photodecomposition, litter quality, and water supply (due to pronounced differences in rainfall among seasons or years) on litter decomposition in semiarid ecosystems. Additionally, we discuss how the interactions among these drivers could account for the high variability in decomposition rates reported in the literature for semiarid ecosystems.

The study was conducted at the southern margin of the Atacama Desert, where rains are restricted to the austral winter months (June-August) and the annual amount of rainfall varies greatly $(<10-300 \mathrm{~mm}$ per year $)$ in response to the climate cycles associated with El Niño Southern Oscillation (ENSO; Jaksic, 2001; Jiménez et al., 2011). We addressed the following hypotheses about litter decomposition in this semiarid environment: (i) Photodecomposition effects during the dry period will carry-over onto subsequent wet period, but such effects may be a function of litter quality; (ii) for a given litter quality the relative importance of carry-over effects would be higher in drier than in wetter years. 


\section{Materials and Methods}

\section{Study Site and Plant Species}

Our study was conducted in the scrublands of Fray Jorge Forest National Park ( $\left.30^{\circ} \mathrm{S}, 71^{\circ} 40^{\prime} \mathrm{W}\right)$, Chile. The local climate is Mediterranean semiarid (López-Cortés and López, 2004), with extremely dry periods extending for 6-7 months (NovemberApril) without rain, followed by humid winters (May-August) when $>95 \%$ of the rain falls. Average annual rainfall for the last 25 years in the study area is $151 \pm 43 \mathrm{~mm}$ (mean $\pm 1 \mathrm{SE}$, $\mathrm{CV}=74 \%$, Gaxiola et al., unpublished data). Higher annual rainfall is largely associated with extreme positive phases of ENSO. For example, 1991-1992 and 1997 have been identified as El Niño years with annual rainfall between 240 and $300 \mathrm{~mm}$. In contrast, years 1988 and 1990 were extremely dry, with an annual rainfall of 11 and $33 \mathrm{~mm}$ respectively, and associated with the negative phase of ENSO, or La Niña years (Gutiérrez et al., 2010; Jiménez et al., 2011). Regarding the focal driver of our study, UV radiation can be extremely high in this area of northern Chile, particularly during the cloudless summer months. According to the Direccion Meteorológica de Chile (DMC; http://www.meteochile.gob.cl/radiacion_uv.php) the UV index for our study site can be higher than 11 at midday during summer months. Similarly, we measured UV radiation in our study site with broadband UV sensors calibrated for 280-320 nm (SU-100, Apogee Instruments Inc., Logan, UT, USA) and recorded unweighted UV mean values of $55 \mathrm{Wm}^{-2}$ during January with an absolute maximum of $62.4 \mathrm{Wm}^{-2}$ (unpublished data).

Predominant vegetation of the study area is a mixed scrubland characterized by the dominance of evergreen and summerdeciduous shrubs, 1-3 $\mathrm{m}$ in height, with a seasonal ground layer of annual species. The thorny evergreen shrub Porlieria chilensis IM Johnst. (Zygophyllaceae) dominates the overstory layer with 25-35\% cover, along with two deciduous species, Proustia pungens D. Don (Asteraceae; $10-20 \%$ cover), and Adesmia bedwellii Skottsb (Leguminosae; 3-6\% cover), leaving ample open spaces between shrubs (Gutiérrez et al., 1993). For the analysis of litter decomposition, we selected two of the dominant shrub species, with contrasting leaf habits: (1) the evergreen Porlieria chilensis and (2) the drought-deciduous Proustia pungens which are henceforth referred to by genus only. These two shrub species differed in leaf mass per area (LMA), foliar nitrogen and carbon content (leaf- $\mathrm{N}$ and leaf-C, respectively), lignin content, and nutrient resorption proficiency (Table S1). We compared litter degradation in these two species not only because these dominate the semiarid vegetation, but also because differences in green leaf traits can persist in senescent leaves and may in turn promote differences in litter quality and decay rates in the field (Cornwell et al., 2008). Leaf litter tends to accumulate under the crown foliage, which is absent during summer in the case of Proustia. Hence leaves of Proustia are exposed to full sun for during the dry season.

\section{Collection of Plant Material}

We collected green leaves and litter from 20 randomly selected adults of each shrub species within an area of about 3 hectares. At least $10 \mathrm{~g}$ of green mature foliage and at least $20 \mathrm{~g}$ (dry weight) of recently fallen dead leaves were collected from under each individual. Green leaves were collected by hand in mid September. To facilitate collection of recently abscised leaves, we placed small litter collectors under each shrub, cleaned weekly to minimize sun exposure of fresh litter. Litter collectors were placed in late spring (mid October) and removed before the onset of summer (early December).

At least 20 leaves per individual were scanned with a HP DeskScan II scanner (Hewlett-Packard, Palo Alto, CA, USA), and images saved at 1200 dpi. Mean leaf area was estimated by counting black pixels on black and white scanned images using Adobe Photoshop 90 (Adobe Systems Incorporated, USA). Leaves were weighed after drying at $65^{\circ} \mathrm{C}$ for 2 days (or until constant weight). Data on leaf mass and area for each species were used to calculate LMA. A total of 14 samples of dried green and dead leaves per species were ground to determine total $\mathrm{C}$ and N concentrations by flash combustion using a NA2500 Carlo Erba Element Analyzer. Lignin content was determined following Van Soest (1963), using one gram of ground litter milled to 1-mm mesh size for acid detergent fiber (ADF). Litter- $\mathrm{N}$ concentrations were interpreted as resorption proficiency (sensu Killingbeck, 1996) after we corrected for changes in LMA, to control for senescence-related differences in leaf carbon.

\section{Photodecomposition Field Experiment}

To assess the effects of natural UV exposure on litter biomass loss for the two shrub species, we established a photodecomposition experiment in the field. The experiment lasted 5 months (December through April), including the entire rainless summer period in semiarid Chile. During the 5 months, we were able to assess the direct effects of natural UV exposure on leaf litter dynamics in the complete absence of rainfall. For this experiment, litter samples (about $5 \mathrm{~g}$ ) were introduced in $15 \times 30 \mathrm{~cm}$ litterbags built with a plastic sheet (UV filter or UV-transmitting film) on the upper side and a plastic fiberglass mesh $(2 \mathrm{~mm})$ in the back; mesh at the bottom provided ventilation and avoided overheating of the litterbag contents. We manipulated UV exposure of the litterbags by using UV-blocking or UV-passing plastic sheets on the sun-exposed side. Solar UV radiation was filtered out by using $125 \mu \mathrm{m}$ UV-blocking film (Mylar-type Cadco clear polyester film, Cadillac Plastic and Chemical, Phoenix, AZ, USA; sharp transmission cutoff below $325 \mathrm{~nm}$ ). For the second group of litterbags, we used Plexiglas UV-transmitting film with a sharp transmission cutoff below 275, thus allowing for $>95 \%$ transmission of the UV-waveband. Litterbags with UV-passing plastic represented "control" conditions (UV+), and litterbags with Mylar plastic filter represented reduced UV radiation (UV-) treatment in the field.

We placed all 180 litterbags, constructed as indicated above (two UV-treatments, two species, 45 replicates), on randomly chosen areas located between shrubs (no shrub cover directly above), about 3-4 $\mathrm{m}$ away from shrubs from which leaf samples were originally collected. Bags were placed in the field in December (onset of the dry period) and kept within the boundary of the 3-hectares study area. We removed dead annual plant material that could cast shade on litterbags. To avoid 
contact between litterbags and the soil directly underneath we lifted each litterbag with wires and anchored them at $\sim 20 \mathrm{~cm}$ above the soil level. Photodecomposition thus reflects only the loss of mass due to solar radiation received by the bags. All litterbags were retrieved in the midst of the austral autumn (late April), 5 months after the initiation of the experiment, and before the onset of the rains. Eight damaged or broken litterbags were eliminated from the experiment. Contents of each litterbag were placed inside sealed plastic bags to avoid dead matter loss and taken to the laboratory for dry mass estimates. These contents were oven-dried at $60^{\circ} \mathrm{C}$ for 2 days and subsequently removed from the mesh and weighed. We took subsamples from all litterbags for determination of total C and N. Subsamples of material from 26 litterbags (per treatment and species) were used for lignin determinations. Using these values we calculated litter-C, litter- $\mathrm{N}$, litter $\mathrm{C}: \mathrm{N}$, and lignin:N ratios for UV+ and UV- treatments and for each of the two shrub species. All chemical analyses were conducted in the laboratory of Agro-analyses from the Faculty of Agronomy and Forest Research, Catholic University of Chile. Photodecomposition effect was estimated as the percentage of litter mass loss over the 5 months period of exposure to full sun. Biomass loss $\%=(($ initial weight - final weight $) /$ initial weight)* 100 .

Every month during the field experiment we monitored temperatures inside 10-15 litterbags per treatment, five times in 1 day, by sticking a mini $k$-thermocouple probe inside the bags. The thermocouple was connected to a SM320 datalogger (Dickson Addison, USA).

\section{Laboratory decomposition experiment}

To test the predictions about the combined effects of photodecomposition and soil moisture on litter decay, we conducted a follow-up decomposition experiment in the laboratory. For this experiment we used litter subsamples taken from the UV- or UV+ litterbags from the photodecomposition experiment. We weighted these subsamples in order to get at least $3 \mathrm{~g}$ of initial dry weight. Each litter sample was placed over a $5 \times 5 \mathrm{~cm}$ square of $2-\mathrm{mm}$ green-fiberglass mesh on the surface of small plastic trays $(15 \times 15 \mathrm{~cm}$ and $5 \mathrm{~cm}$-depth) containing $350 \mathrm{~g}$ of soil collected from the study site. Each litterbag was slightly covered with a less than a teaspoon of soil, as soil particles may promote litter biomass loss (Moorhead and Reynolds, 1991; Barnes et al., 2012). In August-September the total of 132 leaf litter mesh bags ( 2 species $\times 2$ UV treatments $\times 3$ simulated rainfall levels, 11 replicates) were randomly distributed over benches in a controlled temperature-room, where temperature was set at $23^{\circ}$ C. Litter samples were assigned one of the three water treatments that simulated actual ranges of annual rainfall recorded over the past 25 years in the study area: (1) low rainfall or "dry year" (water addition equivalent to $15 \mathrm{~mm}$ of rain), (2) average or "normal year" (equivalent to $140 \mathrm{~mm}$ ), and (3) high rainfall or "wet year" (equivalent to c. $250 \mathrm{~mm}$ ). The latter amount resembles the rainfall of an El Niño event. According to the 25 -years instrumental rainfall records for the study site, in dry years an average rainfall event is about $0.2 \pm 0.1 \mathrm{~mm}$ per day (or $\sim 0.02 \mathrm{ml} \mathrm{cm}^{-2}$ ); for an average year, average daily pulses are $1.1 \pm 0.3 \mathrm{~mm}$ (or $\sim 0.11 \mathrm{ml} \mathrm{cm}^{-2}$ ), and can last 3-6 h; and finally, average pulses on wet years are $2.5 \pm 0.4 \mathrm{~mm}$ (or $\sim 0.25 \mathrm{ml} \mathrm{cm}^{-2}$ ) spread over 10-15 h (Gaxiola et al., unpublished data). Based on this information we established the amount and frequency of water pulses for each water treatment. Water treatments were provided in $\mathrm{ml} \mathrm{cm}{ }^{-2}$, as $0.1 \mathrm{ml} \mathrm{cm}^{-2}$ is equivalent to $1 \mathrm{~mm}$ of rainfall. For the low rainfall treatment, and considering the size of the plastic trays (i.e., $15 \times 15 \mathrm{~cm}$ ) we added pulses of $0.02 \mathrm{ml} \mathrm{cm}^{-2}$. The equivalent of $15 \mathrm{~mm}$ of rain was added after 75 pulses over 2 months. For this treatment we used a pipette. For the treatment equivalent to an average year, pulses of water ranged from 0.5 to $1.1 \mathrm{ml} \mathrm{cm}^{-2}$ until the equivalent of $140 \mathrm{~mm}$ of rainfall was accumulated (after 19 pulses of different magnitudes). To simulate the condition of a wet El Niño year, we added pulses ranging from 0.8 to $2.5 \mathrm{ml} \mathrm{cm}^{-2}$ until the equivalent of $250 \mathrm{~mm}$ was accumulated (i.e., 18 different pulses). For the last two treatments we used trigger water sprayers of different sizes to control the water volume reaching the bags. Water pulses were randomly distributed over the first 4 months of the experiment, with $80 \%$ of the pulses concentrated in the second and third months, as climatic measurements in our study site show that rains are greatest in June and July $(80 \%$ of rainfall).

Every 20 days we shuffled litterbags to reduce effects of position along benches. Six months later, litter samples were ovendried at $60^{\circ} \mathrm{C}$ until constant mass. Biomass loss was monitored over 6 months since the experiment was initiated in the laboratory. Litter decomposition was estimated as the percentage of remaining biomass. Remaining biomass $\%=$ (final weight $/$ initial weight) $* 100$.

\section{Data Analyses}

To assess inter-specific differences in foliar traits for green leaves and leaf litter before and after the photodecomposition experiment, we used pairwise comparisons based on Welch two sample $t$-tests. Effects of differential exposure to natural UV radiation on litter biomass loss were tested using a two-way analysis of variance (ANOVA; Crawley, 2002), with species and UV-treatments as factors.

The laboratory experiment on litter decomposition under different levels of soil moisture was analyzed with a generalized linear model ( $\mathrm{glm}$ routine in $R$ ) to test for the effects of the three irrigation treatments, the carry-over effects of previous photodecomposition in the field (UV treatments), species identity, and litter quality (i.e., litter C:N and lignin:N ratios). We also tested for the interactions among these factors. Decomposition, expressed as remaining litter biomass (\%) was the response variable in the analysis. A full model was fitted to the data and then reduced to a minimal adequate model by removing terms sequentially, starting from the highestorder interaction terms, and using anova command in $\mathrm{R}$ to test for statistical significance of each model term (Crawley, 2002). All data were checked for homogeneity of variances before analyses and appropriate transformations were used as needed. Analyses were done with $R$ (R Development Core Team, 2011). 


\section{Results}

\section{Traits of Green Leaves and Litter}

Proustia and Porlieria differed in green leaf traits in accordance with their contrasting leaf habits. LMA, lignin\% and leaf carbon content as well as $\mathrm{C}: \mathrm{N}$ and lignin: $\mathrm{N}$ ratios were lower for the deciduous Proustia than for the evergreen Porlieria, but total N content was higher in Proustia leaves (Table S1). With regard to litter chemistry, $\mathrm{C}$ and $\mathrm{N}$ contents, and $\mathrm{C}: \mathrm{N}$ ratios did not differ between species, and only lignin and lignin: $\mathrm{N}$ ratios were higher for Porlieria than for Proustia litter (Table S1). Lower litter-N content in Proustia was associated with a strong N-resorption proficiency (i.e., 46\%), which was higher than that of Porlieria (25\% $\mathrm{N}$ resorption; $t=5.9, \mathrm{df}=32, P<0.0001)$. Reductions of litter-N in Proustia resulted in similar C:N ratios in the litter of both species (Table S1). Lignin:N was higher for Porlieria than for Proustia and this difference together with contrasts in LMA could represent a major disparity in litter quality between the two focal species.

\section{Photodecomposition in the Field}

Natural UV radiation significantly reduced litter biomass as seen when data for both species were analyzed together $\left(\mathrm{UV}+=14.8 \pm 1.3\right.$ vs. $\mathrm{UV}-=4.7 \pm 0.13 ; F_{1,136}=144.6$ $P<0.0001)$. We found higher biomass loss in Proustia than in Porlieria (Proustia $=15.1 \pm 1.2$ vs. Porlieria $=4.2 \pm 0.21$; $\left.F_{1,135}=5.6, P<0.001\right)$. In $\mathrm{UV}+$, the litter mass loss for Proustia was almost 25\% whereas for Porlieria it was less than 5\% (Figure 1). The interaction term 'species $\times$ UV treatment' was significant $\left(F_{1,132}=57.3, P<0.0001\right)$. Comparisons between initial and final litter mass weights for UV - treatment showed no significant differences either for Proustia $(5.34 \pm 0.02 \mathrm{~g}$ vs. $5.18 \pm 0.02 \mathrm{~g} ; t=4.11$, d.f. $=70, P=0.16)$, or Porlieria $(5.01 \pm 0.15$ g vs. $4.87 \pm 0.01 \mathrm{~g} ; t=0.87$, d.f. $70, P=0.13)$. Therefore our UV-treatment indeed reduced UV radiation and protected litter from photodegradation.

Overall, photodecomposition changed litter carbon and lignin content altering litter chemistry, particularly in the deciduous

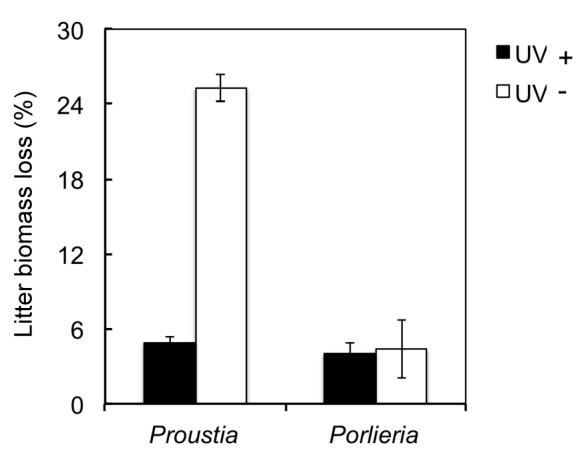

FIGURE 1 | Effects of UV exposure on litter biomass after a 5-months experiment in semiarid Chile. Data shown for deciduous Proustia and evergreen Porlieria. UV - represents a reduction of $96-98 \%$ of natural UV levels; UV+ is the control treatment without UV filters. Data are means $\pm 1 \mathrm{SE}$ (thin bars). species. Proustia litter had lower carbon and lignin content in UV+ than in UV - treatments (Table 1) and such reduced carbon content resulted in lower C:N ratios and lignin: $\mathrm{N}$ in the UV+ treatment (Table 1). In the case of Porlieria, we found no differences in litter chemistry between UV treatments (Table 1). However, we noted that the initial lignin content in Porlieria decreased from 12.46 to $11 \%$ in both treatments (Table S1 and Table 1, respectively), suggesting that exposure to natural solar radiation changed its litter chemistry. Finally, we point out that because there were no changes in litter N\% between UV treatments for either species (Table 1), subsequent changes in litter chemistry could be attributed to carbon losses only.

During the 5-months photodecomposition experiment, we detected minor increases in temperature inside the litterbags $\left(F_{1,4}=2.5, P=0.044\right.$; Figure $\left.\mathrm{S} 1\right)$ and these were associated with higher maximum temperatures in the summer. Thermal environments did not differ between UV treatments $\left(F_{1,1}=0.11\right.$, $P=0.25$; Figure S1) and we must rule out temperature effects on carbon losses.

\section{Laboratory Decomposition Experiment}

Between 2 and $65 \%$ of initial litter mass was lost during the subsequent 6-months of decomposition in the laboratory after water addition. Variation in biomass loss among litter samples was associated primarily with differences among irrigation treatments (i.e., simulated rainfall), but we also detected the carry-over effects from the process of litter photodegradation in the previous field experiment, and effects of species identity (Figure 2).

Experimental water supply strongly enhanced the decomposition of litter samples of both species $\left(F_{1,130}=283, P<00001\right)$ and water supply alone explained $57 \%$ of total model deviance. When all data were pooled there were no differences in remaining biomass between UV treatments across all water addition treatments (UV+: $73.1 \% \pm 2.9$ and UV-: $77.3 \% \pm 3.2 ; F_{1,129}=1.45$; $P=0.22$ ). This could be a consequence of the marked differences in remaining biomass between shrub species $\left(F_{1,128}=113\right.$, $P<0.0001$; Figure 2). The largest difference in litter decomposition between the two shrub species was due to the "high rainfall" treatment (i.e., water addition equivalent to $250 \mathrm{~mm}$ ). In this treatment, at the end of the lab experiment, it remained $75 \%$ of the initial mass of Porlieria and only $25 \%$ of the mass of Proustia. This difference was statistically accounted for the significant interaction term 'species $\times$ water treatment' $\left(F_{1,126}=103\right.$, $P<0.0001)$.

Pre-exposure to UV radiation in the field enhanced litter decomposition only for Proustia (Figure 2A). This effect accounted for the significant interaction term 'species $\times$ UV treatment' $\left(F_{1,125}=55, P<0.01\right)$. Remaining biomass was lower in Proustia litter in the low and medium irrigation treatments when previously exposed to UV, but no differences in decomposition between $\mathrm{UV}+$ and $\mathrm{UV}$ - were observed for the "high rainfall" treatment (Figure 3A). The triple interaction term 'species $\times$ UV treatment $\times$ water treatment' was not significant $\left(F_{1,124}=0.38, P=0.5\right)$. Hence, as expected, carry-over effects of photodegradation in Proustia decreased 
TABLE 1 | Comparisons of leaf litter traits between Proustia and Porlieria following 5 months of photodecomposition in the field.

\begin{tabular}{|c|c|c|c|c|c|c|}
\hline \multirow[b]{2}{*}{ Trait } & \multicolumn{3}{|c|}{ Proustia } & \multicolumn{3}{|c|}{ Porlieria } \\
\hline & UV- & $\mathbf{U V}_{+}$ & $t$ test (d.f.) & UV- & $\mathbf{U V}_{+}$ & $t$ test (d.f.) \\
\hline LMA (g. $\mathrm{m}^{-2}$ ) & $143.2(3.6)$ & 129.7 (1.65) & $6.44(70)^{* * *}$ & 264.8 (3.59) & 263.1 (4.07) & $0.31(70)$ \\
\hline $\mathrm{C} \%$ & $49.4(0.49)$ & $38.1(0.33)$ & $18.5(63)^{* * *}$ & $51.1(0.57)$ & $50.5(0.25)$ & $1.86(54)$ \\
\hline $\mathrm{N} \%$ & 1.07 (0.07) & $1.06(0.04)$ & $0.03(64)$ & $1.11(0.11)$ & $1.12(0.09)$ & $1.00(70)$ \\
\hline C:N & $45.5(0.57)$ & $35.3(0.32)$ & $14.9(57)^{* * *}$ & $46.8(0.68)$ & $44.3(0.39)$ & 1.99 (58) \\
\hline Lignin (\%) & $9.87(0.13)$ & $7.36(0.14)$ & $14.2(72)^{* * *}$ & $11.17(0.19)$ & $11.05(0.15)$ & $0.55(72)$ \\
\hline Lignin:N & $9.34(0.12)$ & $6.82(0.13)$ & $13.4(72)^{* * *}$ & 10.05 (0.18) & $9.80(0.16)$ & 1.01 (70) \\
\hline
\end{tabular}

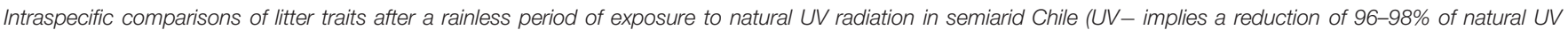
radiation; UV+ is the control treatment with less than $10 \%$ reduction of UV levels). Values are means \pm 1 SE, and student- $t$ tests are given for intraspecific comparisons. $* * * P<0.0001$

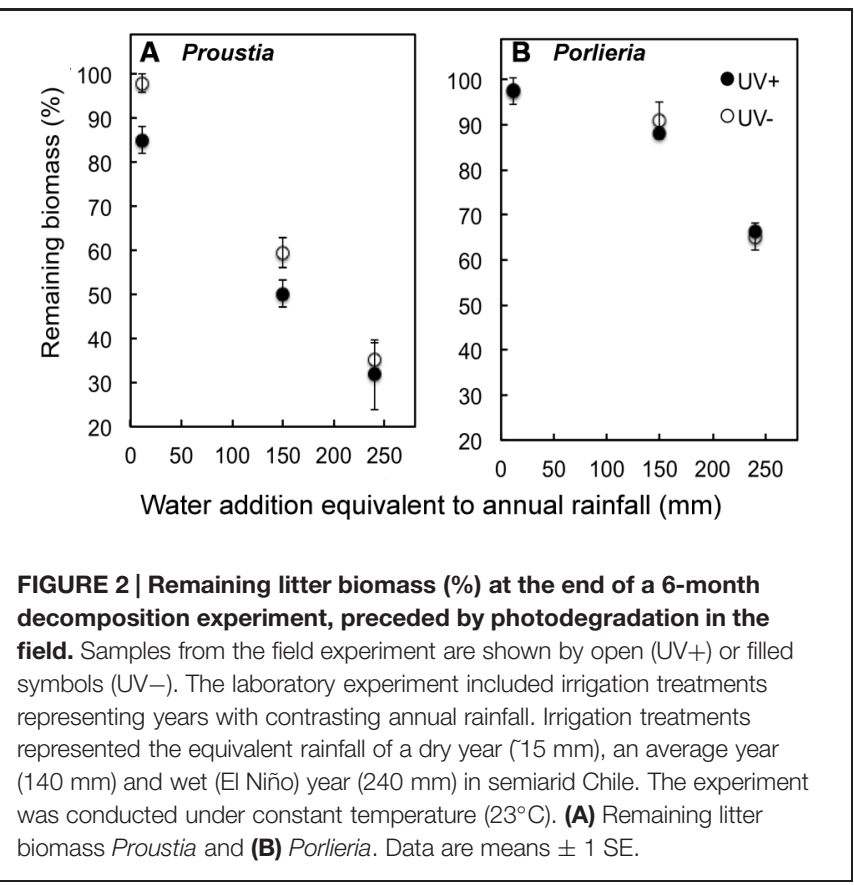

with increasing water supply. Porlieria in turn showed no differences either in the slope or the intercept of the carbon loss vs. water availability relationships between UV treatments (Figure 3B).

\section{Discussion}

Our study offers experimental evidence that interspecific differences in litter quality, in combination with natural UV exposure during dry periods and mass loss during wet periods can promote broad variance in decomposition rates in semiarid ecosystems (Figure 3). Broad variance in decomposition rates has been reported in the literature for semiarid ecosystems around the globe (Zhang et al., 2008).

We show here that litter from drought-deciduous Proustia decayed more rapidly than litter from evergreen Porlieria, which had higher LMA, lignin\% and lignin:N ratios than Proustia (Table 1). Differences in litter chemistry accounted for the marked contrast in decomposition rates between species and among irrigation treatments, independently of pre-exposure to UV radiation (Figure 3). Furthermore, we were able to show that these two coexisting shrub species were able to take advantage of contrasting abiotic factors that promote decomposition in arid lands. In the case of Proustia, UV exposure changes litter quality, which during the wet season can degrade even at low levels of annual rainfall or during dry years (Figures 2 and 3). Therefore, for Proustia, litter pre-exposure to UV radiation produce carry-over effects that promote ensuing microbial decomposition. On the other hand, litter from Porlieria which tends to accumulate directly below the shade of the shrub crown, relies primarily on microbial decomposition and thus on soil moisture levels that promotes microbial activity.

Foliar traits and litter chemistry strongly influence the breakdown of litter by UV exposure (Gallo et al., 2006; Brandt et al., 2007; King et al., 2012); indeed, litter exposure to 5 months of natural UV radiation had strong photochemical effects on Proustia but negligible effects on Porlieria (Table 1). A high proportion of lignin and carbon was lost from Proustia litter during UV exposure in the field, whereas litter chemistry of evergreen Porlieria did not differ between UV treatments (Table 1). Differences in litter biomass loss between the two focal shrub species, could also be accounted for by other factors such as leaf size, which has been shown to influence UV exposure effects on litter decomposition (Gallo et al., 2006; King et al., 2012; Song et al., 2013). Proustia leaves $\left(2 \mathrm{~cm}^{2}\right)$ are much larger than those of Porlieria $\left(<0.5 \mathrm{~cm}^{2}\right)$ and hence on the basis of differences in leaf area we could expect higher effects of ambient UV on Proustia litter. Leaves of Porlieria remain protected under evergreen foliage after falling, but are exposed to high solar radiation levels for long periods while still on the plant. It has been reported that long exposure of green foliage to UV can induce the production of photo-protective compounds, including flavonoids and polyphenols such as tannins (Rozema et al., 1997; Gehrke, 1999). These photo-protective compounds can remain active long after leaf abscission and thus reduce the effect of UV exposure on the degradation of lignin and other carbon compounds.

Our data show that litter of Porlieria had small but nonsignificant carbon losses during the field experiment (cf. values 


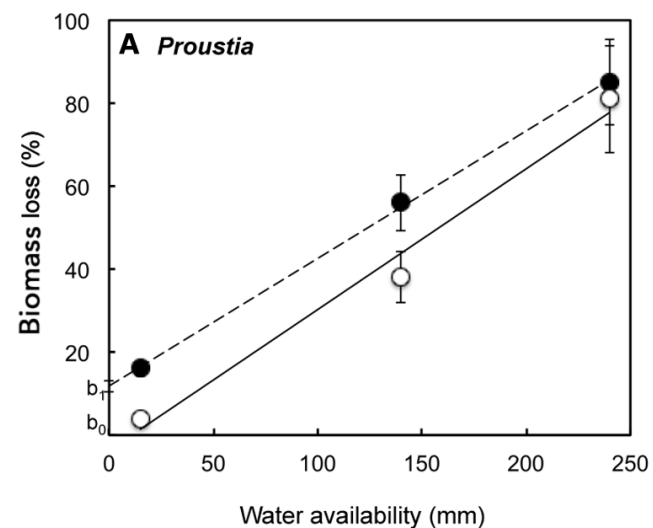

FIGURE 3 | Graphic representation of carry-over effects of photodecomposition on litter biomass losses (\%) as a function of water availability for two shrub species with contrasting leaf traits.

(A) Carry-over effects of UV exposure during the dry summer months promoted further carbon losses from Proustia litter, particularly in the irrigation treatments equivalent to low and average rainfall years, (B) No significant effects of

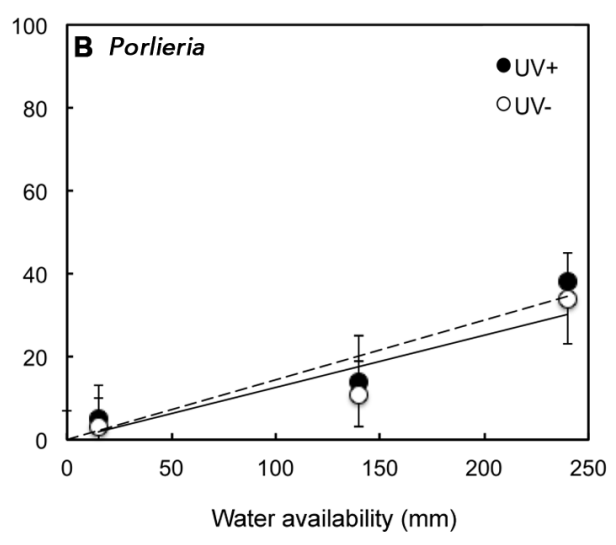

photodecomposition on further biomass losses are observed in the case of Porlieria litter. Lines represent significant relationships between experimental irrigation treatments and biomass loss; dashed lines $=U V+$ (Proustia: $y=0.32 \pm 0.006 x+12.9 \pm 1.07 ; R^{2}=0.95$ and Porlieria: $y=0.123 \pm 0.01 x$ $R^{2}=0.91$ ) and solid lines $=U V-$ (Proustia: $y=0.29 \pm 0.01 x ; R^{2}=0.95$ and Porlieria: $\left.y=0.122 \pm 0.01 x ; R^{2}=0.90\right)$. in Table S1 vs. those in Table 1). This result suggests that sunlight caused only weak degradation of Porlieria litter. Because lignin is a light absorbing molecule (Austin and Ballaré, 2010), it is the most likely carbon compound degraded by sunlight during our field experiment, and according to these authors solar wavelengths such as blue-green quanta can also promote carbon losses in leaf litter. On these grounds, it is likely that in addition to $\mathrm{UV}$, other solar wavelengths may promote the breakdown of carbon in Porliera litter. We cannot document these effects because the radiation filters that we used in the photodecomposition field experiment only blocked UV-B radiation. Furthermore, cellulose and hemicellulose are also susceptible to breakdown by solar exposure (Brandt et al., 2010; King et al., 2012) and photodegradation of these compounds could also contribute to carbon losses observed in Porlieria and in Proustia litter. Further chemical analyses for cellulose and hemicellulose are required to evaluate the extent to which the interaction between solar wavelengths and carbon compounds may account for the differential effects of solar radiation on litter chemistry of coexisting shrub species.

In the lab experiment, which represented the humid phase of the decomposition process in semiarid ecosystems, litter from Proustia decayed more rapidly than litter from Porlieria. To explain this result, we argue that contrasting litter chemistry promoted differences in litter decomposition between species across "rainfall" treatments (Figure 2). These results agree with studies highlighting the importance of litter chemistry on litter decomposition due to positive effects of low C:N and lignin:N ratios (Murphy et al., 1998; Pérez-Harguindeguy et al., 2000). This could be associated with the fact that litter C:N of Proustia was close to 30, and according to a recent review it is close to the optimal C:N ratio for the microbial decomposers (Manzoni et al., 2010). Results from the lab decomposition experiment are in conflict with studies that did not find a strong or significant correlation between litter biomass loss and precipitation amount (Martínez-Yrízar et al., 2007).
In the present study, biomass losses were strongly and positively correlated with increasing simulated "rainfall" (Figure 2). However, we found that for the same water treatment there were marked differences in biomass loss between Proustia and Porlieria (Figures $\mathbf{2}$ and 3). It is worth noting that litter biomass losses for Proustia followed the classical negative exponential function reported for mesic ecosystems, whereas biomass losses from Porlieria litter followed the linear function described for semiarid ecosystems (Austin and Vivanco, 2006; Barnes et al., 2012).

Carry-over effects of photodegradation were only noticeable under low irrigation and these effects became negligible when water supply simulated a high rainfall year (Figure 3A). This result is consistent with our predictions about the relative importance of carry-over photodegradation effects on litter decomposition. In this context, we show that during the dry season litter of Proustia was pre-degraded by natural exposure to UV (and possibly other solar wavelengths) to make it less rich in carbon and recalcitrant compounds (Table 1). Such chemical changes made litter of Proustia more readily degradable by microorganisms under the treatments that simulated low or average rainfall; in the laboratory; in other words, carry-over effects of photodegradation changed the intercept at which litter decomposition started under humid conditions (from b0 to b1 see Figure 3A). Therefore, for a given amount of rainfall, Proustia litter decomposed faster when previously exposed to UV during the dry summer (Figure 2A). Our results provide indirect evidence that litter photodecomposition during extended dry periods could enhance microbial activity during subsequent rainy seasons in "normal" or dry years (Figure 3A). We also show that during high-rainfall years (i.e., El Niño years) when this semiarid ecosystem receives over $250 \mathrm{~mm}$, carry-over effects of previous photodegradation become irrelevant (Figure 2A). In recent decades, annual rainfall has declined significantly in this semiarid region (Jiménez et al., 2011), and season 
as low rainfall years increase in frequency, carbon losses due to photodecomposition during the prolonged dry will become an increasingly important driver of overall litter decomposition and ecosystem nutrient recycling.

These findings are consistent with a model of litter decomposition in arid environments where different leaf traits have strong effects on soil organic matter turnover (Cornwell et al., 2008) and where shrub-induced spatial heterogeneity of soil nitrogen and carbon availability in the ecosystem can strongly affect microbial processes (Gutiérrez et al., 1993; Aguiar and Sala, 1999). In arid regions that are affected by variable climate systems, such as ENSO, photodecomposition will vary greatly in its importance on overall litter degradation depending on interannual fluctuations in rainfall. In dry years, or during long dry spells, litter chemistry will be largely dependent on slow photodecomposition processes modulated by UV exposure on the ground. This is a driver through which litter of some species (e.g., drought-deciduous Proustia in this study) could degrade significantly even at low levels of annual rainfall over several dry years (Figures 2 and 3). This mechanism could facilitate the access of deciduous shrub species to recycled nutrients even during low rainfall (La Niña) years. In contrast, evergreen species such as Porlieria are strongly dependent on high-rainfall (El Niño) years for complete turnover of their organic matter, as facilitated by enhanced microbial activity. We conclude therefore that coexisting shrub species with contrasting leaf traits in semiarid ecosystems can take advantage of different abiotic settings to promote local nutrient cycling. We propose that such interspecific differences, added to temporal and spatial variability in resources and water supply, could enhance the variability in decomposition rates that has been reported for semiarid ecosystems, as well

\section{References}

Aber, J. D., Melillo, J. M., and McClaugherty, C. A. (1990). Predicting long-term patterns of mass loss, nitrogen dynamics, and soil organic matter formation from initial fine litter chemistry in temperate forest ecosystems. Can. J. Bot. 68, 2201-2208. doi: 10.1139/b90-287

Aerts, R. (1997). Climate, leaf litter chemistry and leaf litter decomposition in terrestrial ecosystems: a triangular relationship. Oikos 79, 439-449. doi: $10.2307 / 3546886$

Aguiar, M. R., and Sala, O. E. (1999). Patch structure, dynamics and implications for the functioning of arid ecosystems. Trends Ecol. Evol. 14, 273-277. doi: 10.1016/S0169-5347(99)01612-2

Austin, A. T. (2011). Has water limited our imagination for aridland biogeochemistry? Trends Ecol. Evol. 26, 229-235. doi: 10.1016/j.tree.2011.02.003

Austin, A. T., Araujo, P. I., and Leva, P. E. (2009). Interaction of position, litter type, and water pulses on decomposition of grasses from the semiarid Patagonian steppe. Ecology 90, 2642-2647. doi: 10.1890/08-1804.1

Austin, A. T., and Ballaré, C. L. (2010). Dual role of lignin in plant litter decomposition in terrestrial ecosystems. Proc. Natl. Acad. Sci. U.S.A. 107, 4618-4622. doi: 10.1073/pnas.0909396107

Austin, A. T., and Vivanco, L. (2006). Plant litter decomposition in a semiarid ecosystem controlled by photodegradation. Nature 442, 555-558. doi: 10.1038/nature05038

Barnes, P. W., Throop, H. L., Hewins, D. B., Abbene, M. L., and Archer, S. R. (2012). Soil coverage reduces photodegradation and promotes the development of soil-microbial films on dryland leaf litter. Ecosystems 15, 311-321. doi: 10.1007/s10021-011-9511-1 as cause the decoupling between annual rainfall and the rates of litter biomass loss.

\section{Author Contributions}

AG designed and performed all experiments and co-wrote the paper with JA.

\section{Acknowledgments}

We thank the Corporación Nacional Forestal (CONAF), Chile, for permission to work at Fray Jorge National Park. AG received support from FONDECYT 1110063, and both authors were supported by grants from Millennium Scientific Initiative (Chile) P05-002 and CONICYT, grant PFB-23 both to the Institute of Ecology and Biodiversity (IEB), Chile. Milagros Jiménez and Felipe Albornoz are thanked for providing useful field and laboratory assistance. We thank P.A. Marquet for helpful comments on earlier versions of this manuscript. This is a contribution of Fray Jorge Experimental site to the research program of the Longterm Socio-ecological Research (LTSER) Network of the IEB, Chile.

\section{Supplementary Material}

The Supplementary Material for this article can be found online at: http://www.frontiersin.org/journal/10.3389/fpls.2015.00140/ abstract

Brandt, L. A., Bohnet, C., and King, J. Y. (2009). Photochemically induced carbon dioxide production as a mechanism for carbon loss from plant litter in arid ecosystems. J. Geophys. Res. Biogeosci. 114:G2. doi: 10.1029/2008JG0 00772

Brandt, L. A., King, J. Y., Hobbie, S. E., Milchunas, D. G., and Sinsabaugh, R. L. (2010). The role of photodegradation in surface litter decomposition across a grassland ecosystem precipitation gradient. Ecosystems 13, 765-781. doi: 10.1007/s10021-010-9353-2

Brandt, L. A., King, J. Y., and Milchunas, D. G. (2007). Effects of ultraviolet radiation on litter decomposition depend on precipitation and litter chemistry in a shortgrass steppe ecosystem. Glob. Change Biol. 13, 2193-2205. doi: 10.1111/j.1365-2486.2007.01428.x

Cornwell, W. K., Cornelissen, J. H. C., Amatangelo, K., Dorrepaal, E., Eviner, V. T., Godoy, O., et al. (2008). Plant species traits are the predominant control on litter decomposition rates within biomes worldwide. Ecol. Lett. 11, 1065-1071. doi: 10.1111/j.1461-0248.2008.01219.x

Couteaux, M. M., Bottner, B., and Berg, B. (1995). Litter decomposition, climate and litter quality. Trends Ecol. Evol. 10, 63-66. doi: 10.1016/S01695347(00)88978-8

Crawley, M. J. (2002). Statistical Computing-an Introduction to Data Analysis Using S-PLUS. Chichester: Wiley, 740.

Davidson, E. A., and Janssens, I. A. (2006). Temperature sensitivity of soil carbon decomposition and feedbacks to climate change. Nature 440, 165-173. doi: 10.1038/nature04514

Day, T. A., Zhang, E. T., and Ruhland, C. T. (2007). Exposure to solar UV-B radiation accelerates mass and lignin loss of Larrea tridentata litter in the Sonoran Desert. Plant Ecol. 193, 185-194. doi: 10.1007/s11258-006-9257-6 
Foereid, B., Bellarby, J., Meier-Augenstein, W., and Kemp, H. (2010). Does light exposure make plant litter more degradable? Plant Soil 333, 275-285. doi: 10.1007/s11104-010-0342-1

Gallo, M. E., Porras-Alfaro, A., Odenbach, K. J., and Sinsabaugh, R. L. (2009). Photoacceleration of plant litter decomposition in an arid environment. Soil Biol. Biochem. 41, 1433-1441. doi: 10.1016/j.soilbio.2009.03.025

Gallo, M. E., Sinsabaugh, R. L., and Cabaniss, S. E. (2006). The role of ultraviolet radiation in litter decomposition in arid ecosystems. Appl. Soil Ecol. 34, 83-91. doi: 10.1016/j.apsoil.2005.12.006

Gehrke, C. (1999). Impacts of enhanced ultraviolet-B radiation on mosses in a subarctic heath ecosystem. Ecology 80, 1844-1851. doi: 10.1890/00129658(1999)080[1844:IOEUBR]2.0.CO;2

Gholz, H. L., Wedin, D. A., Smitherman, S. M., Harmon, M. E., and Parton, W. J. (2000). Long-term dynamics of pine and hardwood litter in contrasting environments: toward a global model of decomposition. Glob. Change Biol. 6, 751-765. doi: 10.1046/j.1365-2486.2000.00349.x

Gutiérrez, J. R., Meserve, P. L., Contreras, L. C., Vásquez, H., and Jaksic, F. M. (1993). Spatial distribution of soil nutrients and ephemeral plants underneath and outside the canopy of Porlieria chilensis shrubs (Zygophyllaceae) in arid coastal Chile. Oecologia 95, 347-352. doi: 10.1007/BF00320987

Gutiérrez, J. R., Meserve, P. L., Kelt, D. A., Engilis, A. Jr., Previtali, M. A., Milstead, W. B., et al. (2010). Long-term research in Bosque Fray Jorge National Park: twenty years studying the role of biotic and abiotic factors in a Chilean semiarid scrubland. Rev. Chil. Hist. Nat. 83, 69-98. doi: 10.4067/s0716078x2010000100005

Hättenschwiler, S., and Jørgensen, H. B. (2010). Carbon quality rather than stoichiometry controls litter decomposition in a tropical rain forest. J. Ecol. 98, 754-763. doi: 10.1111/j.1365-2745.2010.01671.x

Henry, H. A. L., Brizgy, K., and Field, C. B. (2008). Litter decomposition in a California annual grassland: interactions between photodegradation and litter layer thickness. Ecosystems 11, 545-554. doi: 10.1007/s10021-0089141-4

Jaksic, F. M. (2001). Ecological effects of El Niño in terrestrial ecosystems of western South America. Ecography 24, 241-250. doi: 10.1111/j.16000587.2001.tb00196.x

Jiménez, M. A., Jaksic, F. M., Armesto, J. J., Gaxiola, A., Meserve, P. L., Kelt, D. A., et al. (2011). Extreme climatic events change the dynamics and invasibility of semi-arid annual plant communities. Ecol. Lett. 14, 227-1235. doi: 10.1111/j.1461-0248.2011.01693.x

Killingbeck, K. T. (1996). Nutrients in senesced leaves: keys to the search for potential resorption and resorption proficiency. Ecology 77, 1716-1727. doi: $10.2307 / 2265777$

King, J. Y., Brandt, L. A., and Adair, E. C. (2012). Shedding light on plant litter decomposition: advances, implications and new directions in understanding the role of photodegradation. Biogeochemistry 111, 57-81. doi: 10.1007/s10533012-9737-9

López-Cortés, F., and López, D. (2004). “Antecedentes bioclimáticos del Parque Nacional Bosque Fray Jorge," in Historia natural del Parque Nacional Bosque Fray Jorge, eds F. A. Squeo, J. R. Gutiérrez, and I. R. Hernández (La Serena: Ediciones Universidad de La Serena), 45-50.

Manzoni, S., Trofymow, J. A., Jackson, R. B., and Porporato, A. (2010). Stoichiometric controls dynamics on carbon, nitrogen, and phosphorus in decomposing litter. Ecol. Monograph. 80, 89-106. doi: 10.1890/09-0179.1

Martínez-Yrízar, A., Núñez, S., and Búrquez, A. (2007). Leaf litter decomposition in a southern Sonoran Desert ecosystem, northwestern Mexico: effects of habitat and litter quality. Acta Oecol. 32, 291-300. doi: 10.1016/j.actao.2007.05.010

Meentemeyer, V. (1978). Macroclimate and lignin control of litter decomposition rates. Ecology 59, 465-472. doi: 10.2307/1936576
Melillo, J. M., Aber, J. D., and Muratore, J. F. (1982). Nitrogen and lignin control of hardwood leaf litter decomposition dynamics. Ecology 63, 621-626. doi: $10.2307 / 1936780$

Moorhead, D. L., and Callaghan, T. (1994). Effects of increasing ultraviolet-B radiation on decomposition and soil organic matter dynamics: a synthesis and modelling study. Biol. Fert. Soils 18, 19-26. doi: 10.1007/BF00336439

Moorhead, D. L., and Reynolds, J. F. (1991). A general model of litter decomposition in the northern Chihuahuan Desert. Ecol. Modell. 56, 197-219. doi: 10.1016/0304-3800(91)90200-K

Murphy, K. L., Klopatek, J. M., and Klopatek, C. C. (1998). The effects of litter quality and climate on decomposition along an elevational gradient. Ecol. App. 8, 1061-1071. doi: 10.2307/2640961

Parton, W., Silver, W. L., Burke, I. C., Grassens, L., Harmon, M. E., Currie, W. S., et al. (2007). Global-scale similarities in nitrogen release patterns during long-term decomposition. Science 315, 361-364. doi: 10.1126/science.1134853

Pauli, F. (1964). Soil fertility problem in arid and semi-arid lands. Nature 204, 1286-1288. doi: 10.1038/2041286a0

Pérez-Harguindeguy, N., Díaz, S., Cornelissen, J. H. C., Vendramini, F., Cabido, M., and Castellanos, A. (2000). Chemistry and toughness predict leaf litter decomposition rates over a wide spectrum of functional types and taxa in central Argentina. Plant Soil 218, 21-30. doi: 10.1023/A:1014981715532

R Development Core Team. (2011). R: A Language and Environment for Statistical Computing $R$ Foundation for Statistical Computing ISBN: 3-900051-07-0. Available at: http://www.R-project.org/ [accessed September 6, 2011].

Rozema, J., Tosserams, M., Nelissen, H. J. M., Vanheerwaarden, L., Broekman, R. A., and Flierman, N. (1997). Stratospheric ozone reduction and ecosystem processes: enhanced UV-B radiation affects chemical quality and decomposition of leaves of the dune grassland species Calamagrostis epigeios. Plant Ecol. 128, 284-294.

Schaefer, D., Steinberger, Y., and Whitford, W. G. (1985). The failure of nitrogen and lignin control of decomposition in a North American desert. Oecologia 65, 382-386. doi: 10.1007/BF00378913

Song, X., Peng, C., Jiang, H., Zhu, Q., and Wang, W. (2013). Direct and indirect effects of UV-exposure on litter decomposition: a meta-analysis. PLoS ONE 8:e68858. doi: 10.1371/journal.pone.0068858

Van Soest, P. J. (1963). Use of detergents in the analysis of fibrous feeds II. A rapid method for the determination of fiber and lignin. J. Assoc. Off. Anal. Chem. 49 , 546-551.

Vossbrinck, C. R., Coleman, D. C., and Woolley, T. A. (1979). Abiotic and biotic factors in litter decomposition in a semiarid grassland. Ecology 60, 265-271. doi: $10.2307 / 1937654$

Whitford, W. G., Steinberger, Y., MacKay, W., Parker, L. W., Freckman, D., Wallwork, J. A., et al. (1986). Rainfall and decomposition in the Chihuahuan Desert. Oecologia 68, 512-515. doi: 10.1007/BF00378764

Zhang, D., Hui, D., Luo, Y., and Zhou, G. (2008). Rates of litter decomposition in terrestrial ecosystems: global patterns and controlling factors. J. Plant Ecol. 2, 85-93. doi: 10.1093/jpe/rtn002

Conflict of Interest Statement: The authors declare that the research was conducted in the absence of any commercial or financial relationships that could be construed as a potential conflict of interest.

Copyright (c) 2015 Gaxiola and Armesto. This is an open-access article distributed under the terms of the Creative Commons Attribution License (CC BY). The use, distribution or reproduction in other forums is permitted, provided the original author(s) or licensor are credited and that the original publication in this journal is cited, in accordance with accepted academic practice. No use, distribution or reproduction is permitted which does not comply with these terms. 